\title{
Improvement of Corrosion Resistance of 13CrMo4-5 Steel by Ni-Based Laser Cladding Coatings
}

\author{
Damian Koclęga, Agnieszka Radziszewska, Stanisław Dymek, Jerzy Morgiel, Łukasz Maj, and Axel Kranzmann
}

\author{
(Submitted September 4, 2019; in revised form April 23, 2020; published online June 12, 2020)
}

\begin{abstract}
The 13CrMo4-5 ferritic steel is commonly used in power plants, due to its favorable mechanical properties. According to EN10028-2, this steel can be used at temperatures up to $570{ }^{\circ} \mathrm{C}$ because of its creep behavior. The inefficient corrosion resistance limits the application of this steel to lower temperatures depending on the gas temperature and slag formation. Therefore, the application of a highly resistant Ni-based coating is proposed to extend the corrosion resistance of elements made of ferritic steel. The corrosion test was performed in an environment containing a mixture of gases, like $\mathrm{O}_{2}, \mathrm{CO}_{x}$, and $\mathrm{SO}_{x}$, and deposited ashes with elements, e.g., $\mathrm{Na}, \mathrm{Cl}, \mathrm{Ca}, \mathrm{Si}, \mathrm{C}$, Fe, and $\mathrm{Al}$. The exposure time was, respectively, $240 \mathrm{~h}, 1000 \mathrm{~h}$ and $4500 \mathrm{~h}$ at a temperature of $600{ }^{\circ} \mathrm{C}$. The oxide scale formed on the $13 \mathrm{CrMo4-5}$ steel was significantly thicker than on the IN686 coating. The microstructure and chemical and phase compositions of the oxide scale were investigated using light optical microscopy together with scanning and transmission electron microscopy techniques. Energy dispersive $x$-ray analyses were preformed when appropriate.
\end{abstract}

Keywords aggressive environments, corrosion resistance, high temperature, Inconel 686, laser cladding

\section{Introduction}

The European Commission's "Energy Roadmap 2050" report about a strategy to achieve low carbon emission energy production by 2050 states that pollution from fossil fuel power plants can be reduced by increasing the thermodynamic working parameters, like higher combustion temperatures and steam pressure (Ref 1). In fact, it has become a challenge to develop material with sufficient physical properties, like: creep resistance, high thermal conductivity, low thermal expansion and corrosion resistance. There are three groups of materials used in fossil fuel power plants: ferritic (ferritic/martensitic) steels, austenitic steels and Ni-based alloys. Ferritic steels are of particular interest because of their notable mechanical proper-

This article is an invited submission to JMEP selected from presentations at The XXII Physical Metallurgy and Materials Science Conference: Advanced Materials and Technologies (AMT 2019) held June 9-12, 2019, in Bukowina Tatrzańska, Poland, and has been expanded from the original presentation.

Damian Koclega, Faculty of Metals Engineering and Industrial Computer Science, AGH University of Science and Technology, Cracow, Poland; and Federal Institute for Materials Research and Testing - BAM, Berlin, Germany; Agnieszka Radziszewska and Stanisław Dymek, Faculty of Metals Engineering and Industrial Computer Science, AGH University of Science and Technology, Cracow, Poland; Jerzy Morgiel and Lukasz Maj, Institute of Metallurgy and Materials Science, Polish Academy of Science, Cracow, Poland; and Axel Kranzmann, Federal Institute for Materials Research and Testing - BAM, Berlin, Germany. Contact e-mails: dkoclega@agh.edu.pl,_radzisze@agh.edu.pl, gmdymek@cyfronet.pl, j.morgiel@imim.pl, 1.maj@imim.pl, and axel.kranzmann@bam.de. ties, such as: strength, thermal conductivity and expansion, which are crucial in power plant construction. Therefore, the creep and corrosion resistance for these alloys have been widely investigated under different conditions: temperature, pressure and environments: containing chlorine, sulfur compounds, ash deposition, super-critical water, $\mathrm{CO}_{2}$ or molten salts (Ref 2, 3). The 13CrMo4-5 chromium-molybdenum steel, together with $16 \mathrm{Mo} 3, \mathrm{~T} 22, \mathrm{~T} 91, \mathrm{~T} 91$ and VM12, is one of the most frequently used materials for boiler construction due to its good strength, plasticity as well as its weldability (Ref 4). The high amount of iron results in the formation of iron oxide, which does not provide adequate corrosion protection. Therefore, one possibility for ferritic steels is to increase the $\mathrm{Cr}$ content, which translates into the formation of chromium oxide. Alternatively, the corrosion resistance can be improved by the application of Ni-based coatings (Ref 5). The commonly used Ni-based alloys are alloy 59, Ni-50Cr, IN625 and its new generation IN686 (Ref 6). The IN625 alloy is well known as a material with protective properties against corrosion. However, niobium in its chemical composition has a strong tendency to create carbides which could decrease corrosion resistance. In the IN686 alloy, the niobium content was replaced by a more stable tungsten element. There is a lack of information about the corrosion behavior of these alloys, especially in harsh environments consisting of sulfur compounds. The purpose of the study was to investigate the corrosion behavior of Ni-based coatings in environments containing aggressive elements, like sulfur, calcium, potassium, chlorine and iron oxide, using advanced electron microscopy.

\section{Experimental Materials and Methods}

The complexity of Ni-based alloy chemical compositions causes difficulties in the creation of coatings with satisfactory properties. One of the methods used to fabricate coatings is an additive manufacturing technique called the laser cladding process. This process allows a high-quality coating to be produced 
from various alloys for components with complex shapes (Ref 5, $6)$. Laser cladding is based on the parallel melting of the substrate surface and the injection material of the coating as powder or wire. In the applied method, the powder is injected into the melt pool where it is mixed with the substrate material. The performed coating is characterized by excellent metallurgical bonding with the material substrate, lack of porosity and low surface roughness. The process of coating deposition with the Ni-based alloy powder (IN686) using the laser cladding process on the low carbon 13CrMo4-5 steel has been described in detail in (Ref 7, 8). The chemical compositions of the substrate and IN686 powder used for the cladding process are presented in Table 1 . The preliminary microstructure investigations of the polished sections of the coatings were performed with an FEI, Nova NanoSEM 450 scanning electron microscope (SEM). The EBSD orientation maps were acquired with a LEO $1530 \mathrm{VP}$ SEM at a $70^{\circ}$ tilt with regard to the horizontal line. All data were collected at the acceleration voltage of $20 \mathrm{kV}$ with a working distance of $19 \mathrm{~mm}$.

The crystal orientation map was created using an inverse pole figure (IPF).

Details of the microstructure phase composition of the oxide scale were identified with a Tecnai FEG $(200 \mathrm{kV})$ transmission electron microscope (TEM). Specimens for the investigations were cut using a Quanta 3D focused ion beam (FIB).

\subsection{Corrosion Experiment}

The corrosion test was performed through the classical coupon test, described in detail previously (Ref 9, 10). Prior to the corrosion test, small areas of the top of the samples were covered with a gold layer (marker). This helped to differentiate between inward and outward diffusion on the alloy elements under this specific corrosion condition. The samples placed into the furnace chamber were exposed to two variations of hightemperature corrosion tests: firstly - in a mixture of the aggressive gases: $\mathrm{CO}_{2}, \mathrm{H}_{2} \mathrm{O}, \mathrm{N}_{2}, \mathrm{O}_{2}$, and $\mathrm{SO}_{2}$ or secondly-in a mixture of aggressive gas and deposits of ash containing $\mathrm{Fe}$, $\mathrm{O}, \mathrm{Si}, \mathrm{Ca}, \mathrm{Cl}, \mathrm{Na}, \mathrm{C}, \mathrm{Al}, \mathrm{K}, \mathrm{Mg}$, and $\mathrm{S}$. The relative amounts of the ash compounds are presented in Table 2. The experiment was carried out for 240, 1000 and $4500 \mathrm{~h}$ at a temperature of $600{ }^{\circ} \mathrm{C}$ and a pressure of $1 \mathrm{bar}$ in the furnace chamber.

\section{Results and Discussion}

\subsection{Light Optical Microscopy Observations}

Figure 1(a) shows the Ni-based coating created by the laser cladding process.

The coating consists of three layers; the first layer is a result of interaction between the laser beam and substrate, which leads to the melting and mixing of the IN686 powder and base material (13CrMo4-5 steel). In turn, the melting of the substrate introduces iron to the first layer of the coating, which leads to a reduction in the corrosion resistance.

This is associated with the formation by iron of less protective oxide. Therefore, it is necessary to apply two more layers to obtain a composition of the coating related to the original Ni-based powder. The laser cladding has a structure typical for cast metals, i.e., a homogeneous liquid has been transformed into a heterogeneous solid as a consequence of the solidification process. Even though the solidification of the coating occurs at high cooling rates $\left(10^{6} \mathrm{~K} / \mathrm{s}\right)$, it still shows a

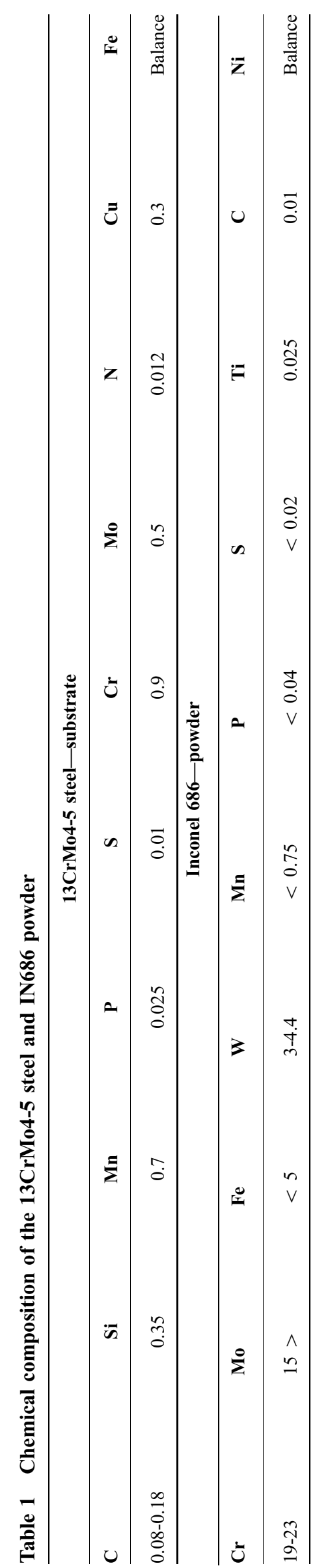


Table 2 Ash composition used in corrosion experiments

\begin{tabular}{|c|c|c|c|c|c|c|c|c|c|}
\hline Compounds & $\mathrm{CaSO}_{4}$ & $\mathrm{Fe}_{2}\left(\mathrm{SO}_{4}\right)_{3}$ & $\mathrm{SiO}_{2}$ & $\mathrm{FeSO}_{4}$ & $\mathrm{Fe}_{2} \mathrm{O}_{3}$ & $\mathrm{Al}_{2} \mathrm{O}_{3}$ & $\mathrm{CaO}$ & $\mathbf{K}_{2} \mathbf{S}_{7} \mathbf{O}_{5}$ & $\mathrm{NaCl}$ \\
\hline Composition, \% & 37.5 & 18.7 & 9.4 & 18.7 & 3.1 & 1.8 & 4.5 & 3.2 & 3.2 \\
\hline
\end{tabular}

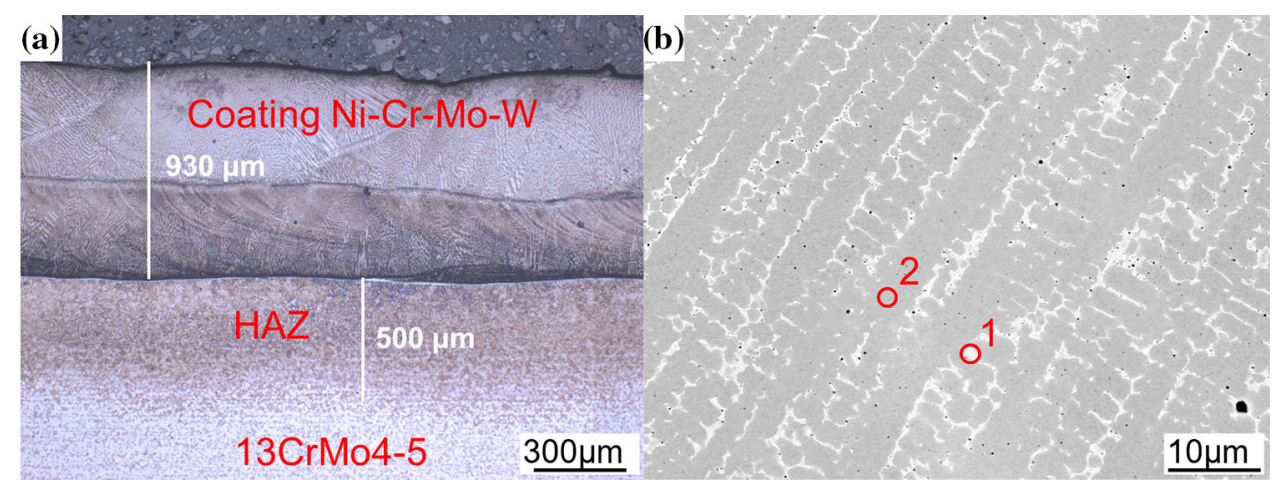

Fig. 1 Micrographs of the IN686 coating microstructure obtained after the laser cladding process: (a) light microscopy (LM), (b) scanning electron microscopy (SEM) with energy dispersive x-ray spectroscopy (EDS) analysis of: interdendritic regions (area 1), dendrite core (area 2)

Table 3 Chemical composition of the IN686 coating

\begin{tabular}{lcccccc}
\hline Area/element, wt.\% & Ni & Cr & Mo & W & Fe & Mn \\
\hline 1-Interdendritic & 47.3 & 17.8 & 24.5 & 6.2 & 3.1 & 1.1 \\
2-Dendrite core & 56.8 & 16.1 & 16.3 & 5.8 & 4.1 & 0.9 \\
\hline
\end{tabular}

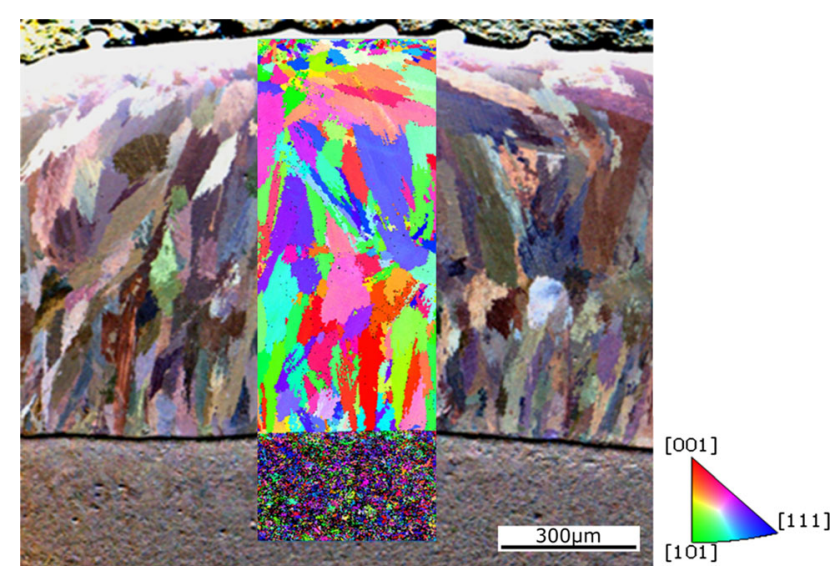

Fig. 2 Crystal orientation map obtained by electron backscatter diffraction (EBSD) for clad layer and heat affected zone

tendency toward micro-segregation (Fig. 1b). A study by energy-dispersive $\mathrm{x}$-ray spectroscopy revealed that, in the interdendritic zones, the amount of molybdenum, chromium and tungsten is higher than in the dendrite core (Table 3).

The tendency of such segregation to interdendritic regions of the named elements was also documented in other experiments (Ref 8-13). Since the refractory elements are responsible for improvement of the corrosion resistance, it is expected that such segregation may have a positive effect on the corrosion protection of the areas of grain boundaries, which are commonly the first to be attacked by corrosion. Figure 2 shows the EBSD map of the inverse pole figure (IPF) obtained from the cross section of the three layer coating. It revealed a significant difference between the grain size of the coating and base material. The top of the coating was characterized by a very fine crystalline structure. In the first layer, the crystals grew parallel to the substrate surface, whereas the second and third layers continued to grow in this direction with a slight tilt toward the cladding direction. The grains were elongated in the growth direction, but their size was within $30-80 \mu \mathrm{m}$, which is several times bigger than the substrate grain size. The surface texture and grain size has a significant influence on the chromium diffusion in the upper surface of the material. The effect of surface preparation was reported by Ostwald and Grabke (Ref 14) for steels containing Cr. The results of the investigation clearly showed that rich deformation of the surface creates fast diffusion paths for $\mathrm{Cr}$.

This is especially true in temperatures below $700{ }^{\circ} \mathrm{C}$, where in general $\mathrm{Cr}$ diffusion in the bulk is slow. In the investigated Ni-based alloy, the characteristic interdendritic regions contain more $\mathrm{Cr}$ and $\mathrm{Mo}$ (Table 3), therefore they are considered as fast diffusion paths, which can supply the surface with those elements. It was confirmed, after $1000 \mathrm{~h}$ of the corrosion test, in areas with interdendritic regions, that the chromium and molybdenum content increased significantly, Fig. 9(b) - area 2. It should be mentioned that there is a difference between the oxide layer formed on the steel after corrosion in a gas environment with and without ash deposition (Fig. 3a and b). In fact, during the short exposure time $(240 \mathrm{~h})$, the direct contact between the gas phase and material is disrupted by the ash layer. The oxidation kinetic for the experiment with ash deposition slowed down and changed the corrosion condition on the metal surface. The activity of oxygen decreased, and a hematite layer could not be identified in any measurable amounts. From one point of view, ash forms an additional barrier to aggressive gas; however, it also keeps gas elements between the ash and the coating surface, resulting in longer reaction times of the gas-material surface. A change of situation 


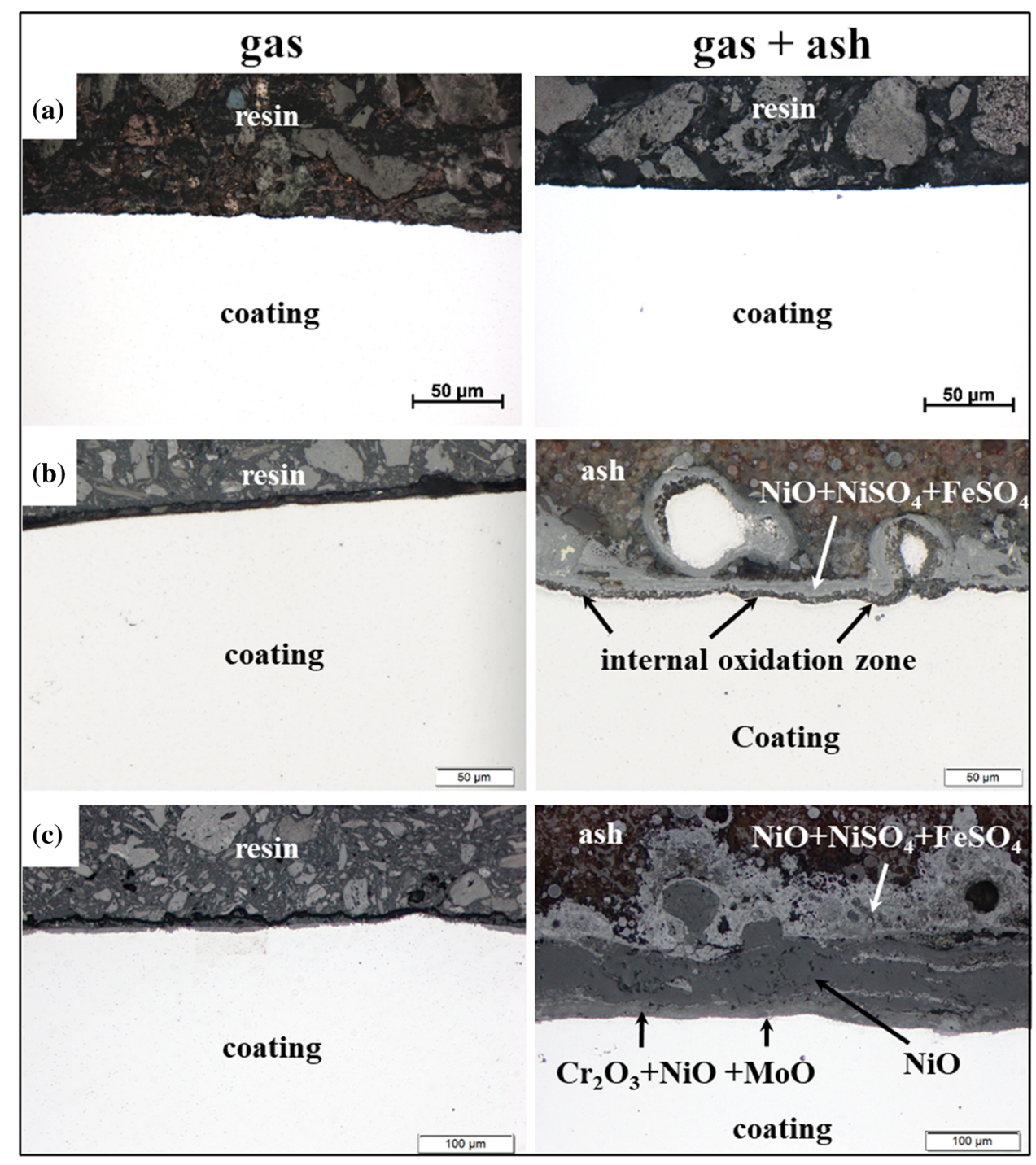

Fig. 3 LM images of the oxide scale which grew on the $13 \mathrm{CrMo} 4-5$ steel after gas corrosion and gas + ash deposit corrosion experiments, respectively, for exposure time: (a) $-240 \mathrm{~h},(\mathrm{~b})-1000 \mathrm{~h},(\mathrm{c})-4500 \mathrm{~h}$

occurs when an ash layer transforms from a powder to a porous, solid state. Hence, the liquids can form locally, and diffusion may accelerate. It can be seen that, after 1000 and $4500 \mathrm{~h}$ exposure time, the corrosion rate increases dramatically. The ash contains elements such as iron, calcium, potassium sulfate and chlorine compounds, which enrich the aggressive character of the environment and have a significant influence on the acceleration of the oxidation processes. Likewise, the same difference between the corrosion character in gas and gas + ash atmospheres was observed for the coating (Fig. 4a and b). During the short exposure time of $240 \mathrm{~h}$, the thickness of the oxide scale is similar for both media. However, after $1000 \mathrm{~h}$ and especially after $4500 \mathrm{~h}$ with ash deposition, specimens oxidized considerably faster. The created oxide scale can be divided into an external scale, containing $\mathrm{NiO}$ and $\mathrm{NiSO}_{4}$, and an internal one with the $\mathrm{Cr}_{2} \mathrm{O}_{3}, \mathrm{MoO}$, and $\mathrm{Cr}_{2} \mathrm{NiO}_{4}$ oxide (Fig. 4b). The presence of respective phases was estimated based on the EDS measurements (according to the Ellingham diagram, the oxygen partial pressure is comparably high when $\mathrm{NiO}$ can be formed). The multi-phase oxide layer structure of Ni-based superalloys has already been observed by researchers
(Ref 15) and was reported under cyclic oxidation behavior of nickel alloy with a higher amount of aluminum. The experiment was carried out at $1100{ }^{\circ} \mathrm{C}$ for up to $200 \mathrm{~h}$ in air. According to XRD results from the material surface, the alloy showed a tendency to create multi-phase oxide with the change of total volume, respectively, for longer cyclic oxidation time.

The authors observed the creation of $\mathrm{NiO}$ on the top of the surface together with $\mathrm{Cr}_{2} \mathrm{O}_{3}, \mathrm{Al}_{2} \mathrm{O}_{3}$ and the spinels $\mathrm{NiCr}_{2} \mathrm{O}_{4}$, $\mathrm{NiAl}_{2} \mathrm{O}_{4}$. During the cyclical oxidation, the $\mathrm{NiO}$ oxide subject to the spallation effect left the $\mathrm{Al}_{2} \mathrm{O}_{3}$ layer on the top of the surface (Ref 16). It is important to mention that most of the available corrosion experiments for Ni-based alloys in the literature were performed at significantly higher temperatures than in this work, where the typical working temperatures in power plants were applied. The impact of temperature was present during the oxidation of IN617 in air at different temperatures, from 750 to $1000{ }^{\circ} \mathrm{C}(\operatorname{Ref} 17)$.

The measured weight gain was several times lower for the experiment performed at $750{ }^{\circ} \mathrm{C}$ than for $1000{ }^{\circ} \mathrm{C}$. In addition, the $\mathrm{Kp}$ (parabolic growth rate constant) increased significantly with higher temperatures. The sequence of oxide formed at 


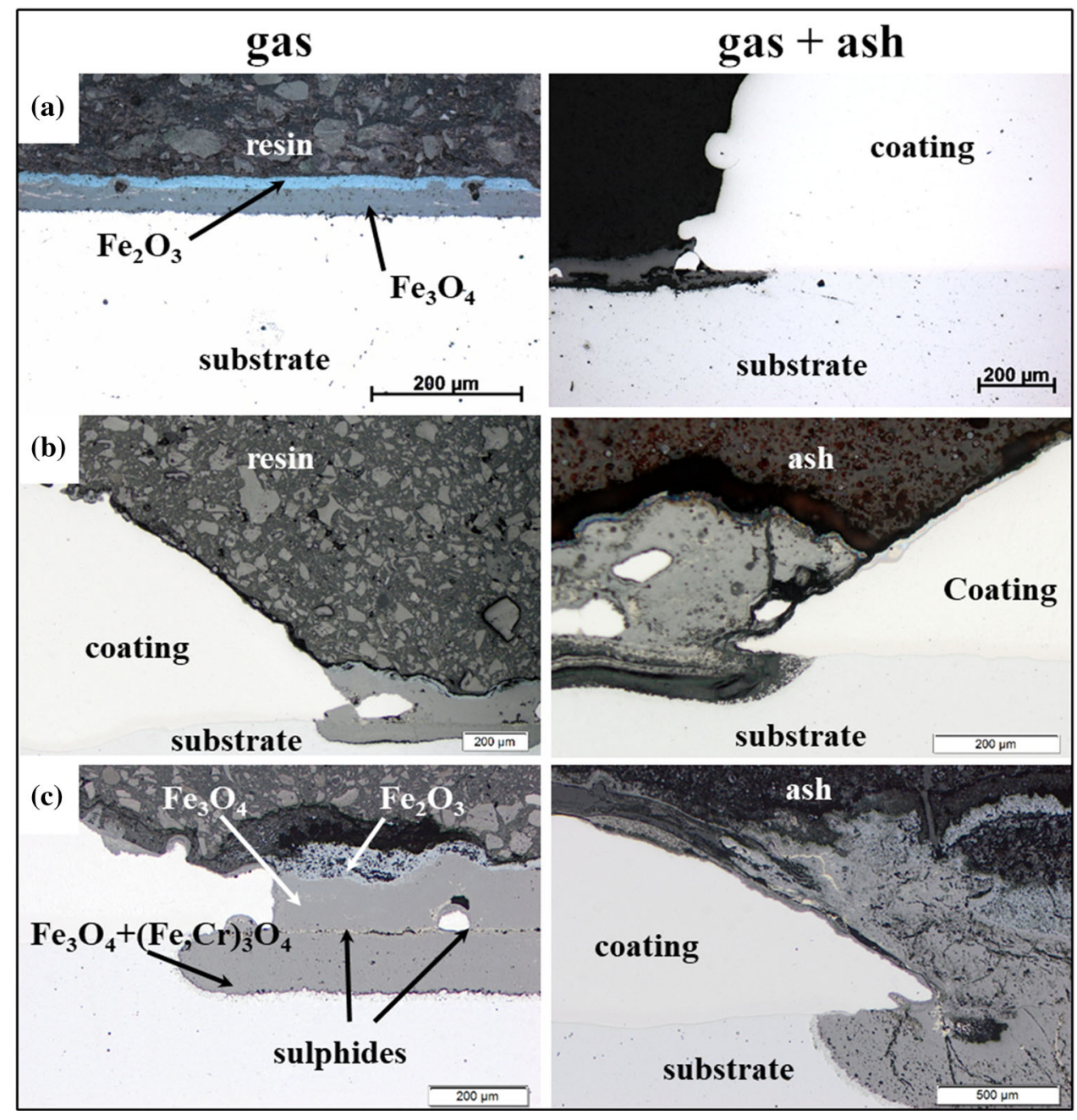

Fig. 4 LM images of the oxide scale revealed on the coating (IN686) after gas corrosion and gas + ash deposit corrosion experiments, respectively, for exposure time: (a) $-240 \mathrm{~h},(\mathrm{~b})-1000 \mathrm{~h},(\mathrm{c})-4500 \mathrm{~h}$
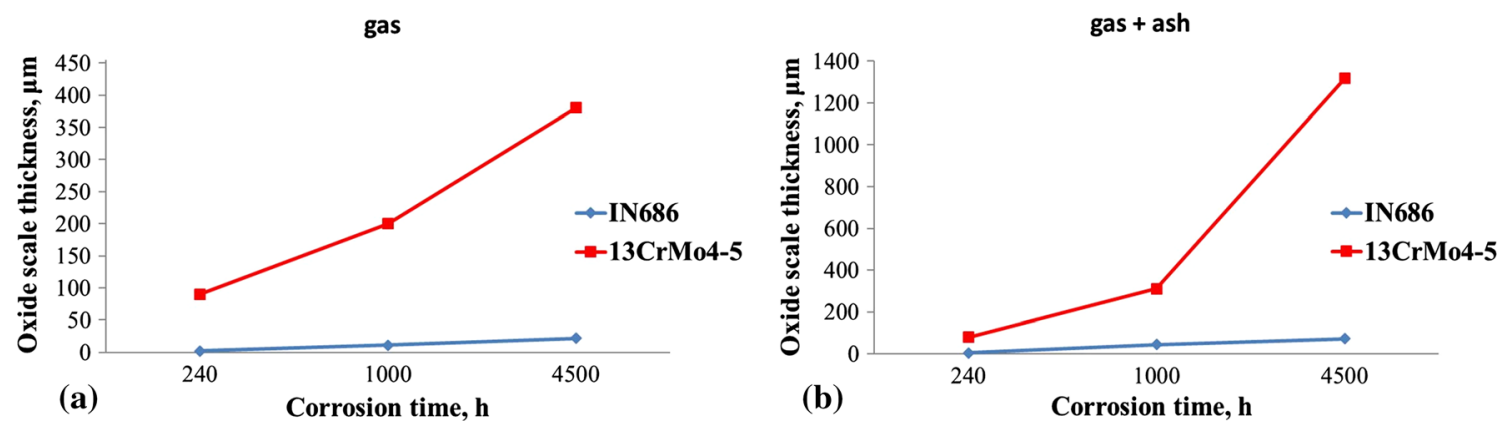

Fig. 5 Comparison of oxide scale thickness for steel and Ni-based alloy, (a) - after gas corrosion, (b) - after gas + ash corrosion

different temperatures stays the same; however, its stability changes, which affects corrosion resistance. The chromium and aluminum oxide is only stable under the described conditions, however, as the authors mentioned, the content of aluminum in the IN617 alloy is too low (about 1.2 wt.\%) to establish a continuous and protective oxide layer. Apart from the temperature, the environment also has an impact on the broader degradation of the material. In fact, the influence of environments is present in the thickness of the formed oxide scale for the testing period (Fig. 5). The measurements show significant improvement for the corrosion resistance compared to uncoated steel. For gas corrosion tests, the thickness of the coating oxide scale is nearly 26 times smaller than for steel $(15-380 \mu \mathrm{m})$. Due to the very aggressive environment in the corrosion test, which includes both gas and ash media, the oxide is 8-10 times thicker than in the gas corrosion test. In terms of the $13 \mathrm{CrMo} 4-5$ steel, the internal oxidization zone (considered as a material loss) reaches about $500 \mu \mathrm{m}$, which is $12.5 \%$ of the steel thickness $(8 \mathrm{~mm})$, while the oxide formed on the coating is around $80 \mu \mathrm{m}$, which is about $9 \%$ of the coating thickness $(930 \mu \mathrm{m})$. 


\subsection{Scanning Electron Microscopy Observation of the Oxide Scale}

The detailed investigations of oxide scale formed on the Nibased coating were performed using a scanning electron microscope (FEI, Nova NanoSEM 450) with an EDS detector. Observations confirmed the double layer character of oxide zones: internal and external oxide regions, parallel in the same samples, have been marked in gold, which was used to distinguish between the inward and outward diffusion of elements (visible in Fig. 6a for 240 and 4500 h). Analysis of the chemical composition of oxide scale shows higher amounts of elements like: oxygen, sulfur, nickel and iron in the external oxide zone, which suggests the formation of nickel oxide, nickel or iron sulfate as the first reaction between the corrosion atmosphere and alloy surface (Fig. 6). After longer exposure time, the external oxide zone became thicker than the internal one. This indicates the faster oxidation of $\mathrm{Ni}$ and appearance of pores in the $\mathrm{NiO}$ structure, which accordingly increases the total volume of the external oxide zone. The diffusion of $\mathrm{Ni}$ from the coating material is not stopped by the formation of chromium and molybdenum oxide. Meanwhile, the internal oxide zone becomes depleted with nickel and leaves this region enriched in chromium and molybdenum.

This phenomenon is clearly visible in the element map distribution after investigation by electron microprobe analysis (EPMA) using Jeol JXA-8900-RL equipment. It can be seen in Fig. 7 that nickel and iron dissolved due to reactions with oxygen and sulfur, at the same time leaving chromium and molybdenum in the internal oxidation zone. The sulfur at the beginning of the corrosion process deposits on the material surface layer and starts its reaction with nickel and iron leading to the formation of the external oxide scale (Fig. 7).

The corrosion experiment with ash deposition increases the oxidation-corrosion reactions between the material surface and gas environment. The distribution of elements in ash powder is not homogeneous; therefore, the corrosion attack has a local character, and strongly depends on the content of ash elements such as: sulfur, chlorine, calcium, iron, magnesium, sodium or potassium (Fig. 8). In fact, the oxidation of material in gas and ash environments behaves more irregularly and cannot be

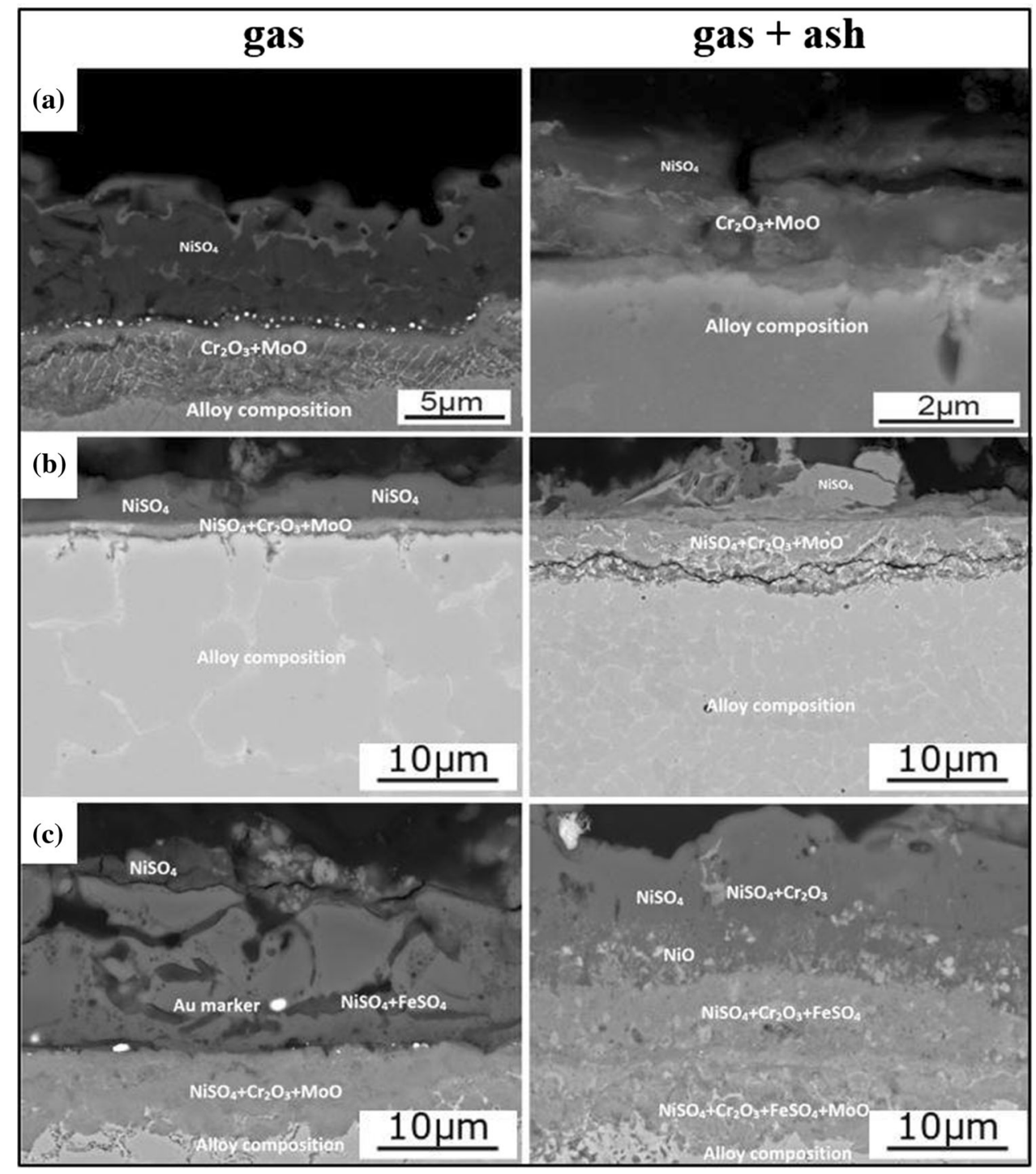

Fig. 6 SEM images of the oxide scale revealed on the coating (IN686) after gas corrosion and gas + ash deposit corrosion experiment, respectively, for exposure time: (a) $-240 \mathrm{~h}$, (b) $-1000 \mathrm{~h},(\mathrm{c})-4500 \mathrm{~h}$ 


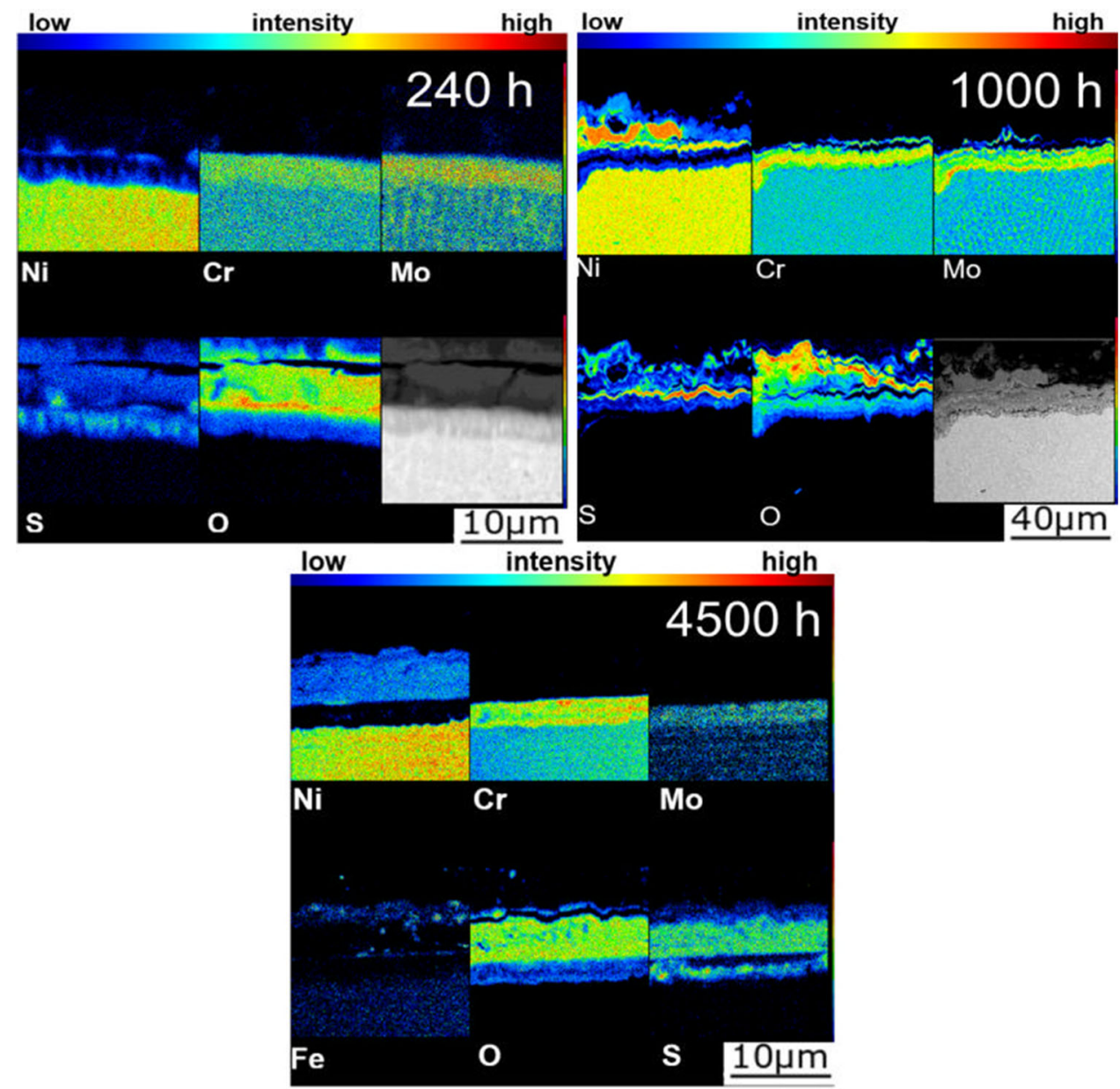

Fig. 7 EPMA (electron microprobe analysis) images of the elements distribution in the oxide scales created on the coatings (IN686) after gas corrosion, respectively, for exposure time 240,1000 and $4500 \mathrm{~h}$

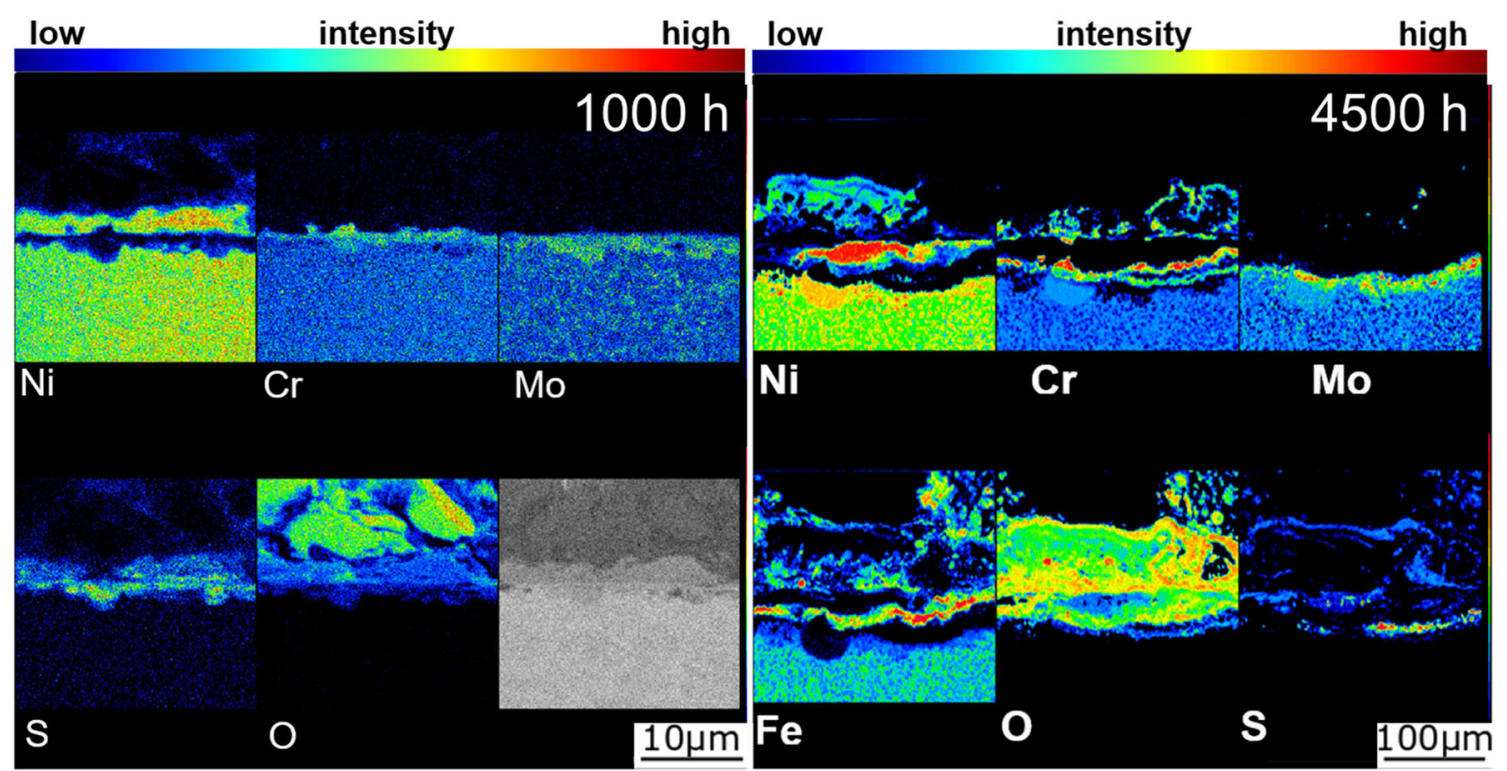

Fig. 8 EPMA images of the elements distribution in the oxide scale created on the IN686 coating after gas + ash corrosion, respectively, for exposure time 1000 and $4500 \mathrm{~h}$ 
discussed as a layered oxide structure. The ash elements react with $\mathrm{Ni}$ and $\mathrm{Cr}$, which results in the mass transport into the ash layer. Additionally, the limitation of gas diffusion into the material interface results in the formation of compact protective oxide layers being hindered.

\subsection{TEM Examinations of the Oxide Scale}

Observation by TEM confirmed the cellular-dendritic structure of the IN686 coating.

The chemical composition analysis (EDS) indicated that the dendrite core is depleted with Mo (10.2 wt.\%), Cr (16.9 wt.\%) and W (1.8 wt.\%), compared to the content of the interdendritic regions (Fig. 9a, area 1, Table 3), where the amount of those elements was, respectively: Mo (26.8 wt.\%), Cr (19.5 wt.\%) and $\mathrm{W}(4.1 \mathrm{wt} . \%)$. The iron content for both microstructure regions was similar. Figure $9 \mathrm{~b}$ shows the microstructure of the sample after $1000 \mathrm{~h}$ of gas corrosion, with the white area (Fig. 9b, area 3) possibly being considered as the oxidation path between interdendritic areas and the dendritic core. The corrosion mechanism is of the intergranular type, passing through grain boundaries as described by others (Ref 9-14, 18).

The presence of the concentration gradients leads to a preferential attack in the dendritic cores, close to the interdendritic zone (Fig. 9b, area 3, Table 4). This phenomenon occurs in the dendritic structure of coatings and can be explained by the micro-segregation of Mo and $\mathrm{Cr}$ (Fig. 9b, area 1-3) into interdendritic regions (Table 4). Simultaneously, sulfur was absent in all these regions. However, it should be remembered that the information during the TEM/EDS chemical analysis comes from a very small area. In view of this fact, the information about chemical composition should be compared with the phase identification performed by selected area diffraction, as shown in Fig. 10 and 11. Additionally, thermodynamic calculations should be performed to decide on the stability of different phases.

The presence of $\mathrm{NiO}$ indicates a high oxygen activity, while sulfides in such coatings might be unstable. The oxide layer can be separated into two zones: on the top of the scale the amorphous nickel oxide (Fig. 10, dyf.1), below the crystalline chromium-nickel spinel $\left(\mathrm{Cr}_{2} \mathrm{NiO}_{4}\right)$ (Fig. 10, dyf.2). It is generally accepted that, under the oxidizing atmosphere, the deposited coatings should have a tendency to form nickel and chromium oxide to ensure corrosion protection (Ref 12-17, 19). Nevertheless, the calculations of the thermodynamic conditions for the oxidation of $\mathrm{Ni}-\mathrm{Cr}$ alloys indicate that the nickel atoms can be captured in the rock-salt or corundum crystallography for many compositions. As a result, there is a wide range of oxide types that can be good insulators, n-type or p-type semiconductors. This means that the nickel-chromium oxide cannot guarantee sufficient corrosion protection, and therefore the formation of chromium oxide is desirable (Ref 20). Respectively to the Ellingham diagram (Ref 21) for Gibbs energy, in the present corrosion test: temperature, pressure of oxygen and water, nickel showed a higher tendency to form oxide than chromium (assuming no sulfur was present in the system). The investigation by TEM of the oxide scale formed after $1000 \mathrm{~h}$ of corrosion experiments in gas and ash atmospheres revealed, independently, that the additional deposition of an ash layer has a significant impact on the oxidation of this material. The oxide scale was thicker and consisted of one
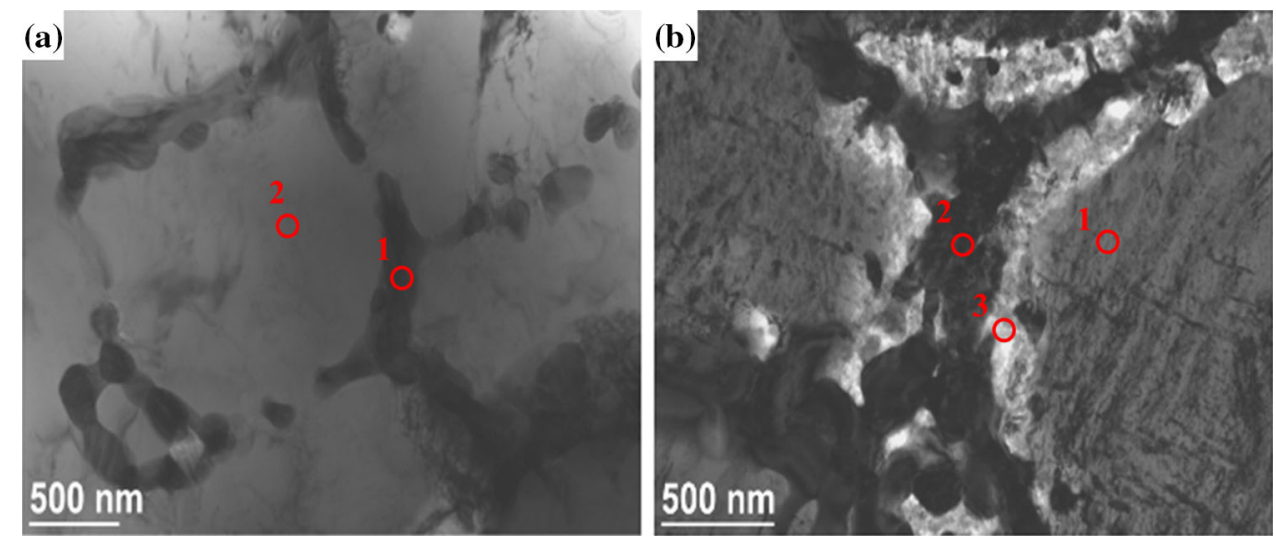

Fig. 9 TEM image of the IN686 coating: (a) — before corrosion test, (b) —after $1000 \mathrm{~h}$ of gas corrosion

Table 4 Chemical composition analysis of the IN686 coating: before (A) and after (B) corrosion test

\begin{tabular}{|c|c|c|c|c|c|c|c|c|}
\hline Variable/element, wt.\% & $\mathbf{N i}$ & $\mathrm{Cr}$ & Mo & $\mathbf{W}$ & Mn & $\mathrm{Fe}$ & $\mathbf{O}$ & $\mathbf{S}$ \\
\hline \multicolumn{9}{|l|}{ [A] } \\
\hline Area 1 & 42.2 & 19.5 & 26.8 & 4.1 & $\ldots$ & 7.4 & $\ldots$ & $\ldots$ \\
\hline Area 2 & 63.9 & 16.9 & 10.2 & 1.8 & $\ldots$ & 7.2 & $\ldots$ & $\ldots$ \\
\hline \multicolumn{9}{|l|}{ [B] } \\
\hline Area 1 & 68.5 & 15.2 & 8.2 & $\ldots$ & $\ldots$ & 8.1 & $\ldots$ & $\ldots$ \\
\hline Area 2 & 27 & 57.2 & $\ldots$ & $\ldots$ & $\ldots$ & $\ldots$ & 15.8 & $\ldots$ \\
\hline Area 3 & 44.1 & 3.7 & 41.2 & 6.1 & $\ldots$ & 4.9 & $\ldots$ & $\ldots$ \\
\hline
\end{tabular}




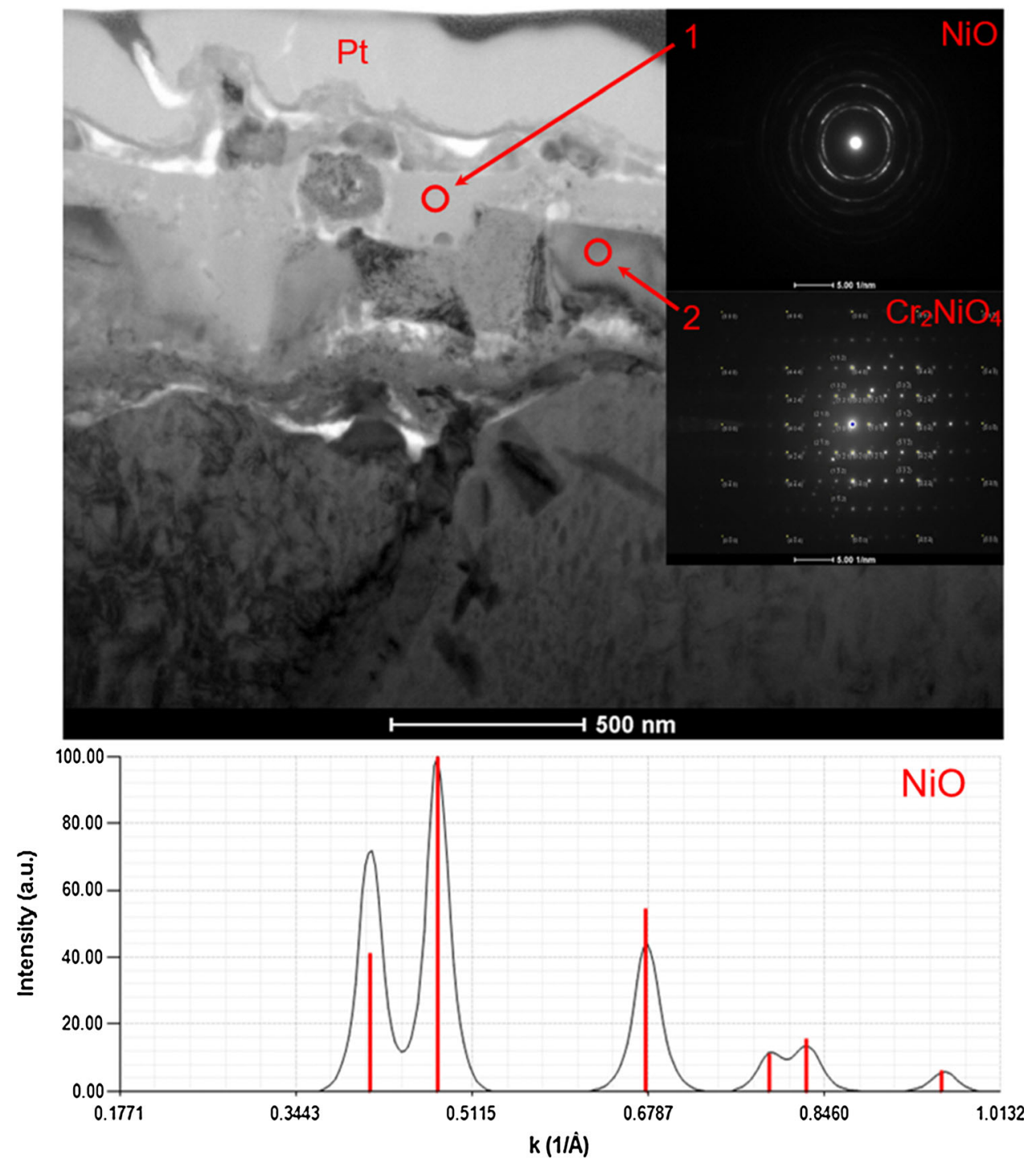

Fig. 10 Lamella of the IN686 coating exposed to a gas atmosphere for $1000 \mathrm{~h}$ at $600{ }^{\circ} \mathrm{C}$. TEM bright field image of oxide scale with diffractions: $1-\mathrm{NiO}$ and $2-\mathrm{Cr}_{2} \mathrm{NiO}_{4}$

additional molybdenum-rich zone (Fig. 11, dyf.1). In contrast with gas corrosion, the investigations in this case showed the presence of sulfur and molybdenum (dyf. 1) as well as iron (dyf. 2). Diffraction no. 3 indicates the alloy matrix Ni- $\gamma$ phase. Sulfur was one of the major compounds of the ash in relation with iron, potassium and calcium. The destructive nature of ash is strengthened by two phenomena: firstly, the enrichment of sulfur in the ash composition and, secondly, the increase of partial pressure in the interface between the oxide scale and ash layer.

\subsection{X-ray Diffraction Pattern of the Oxide Scale}

The $\mathrm{x}$-ray examinations were carried out with an x-ray diffractometer-Panalytical Empyrean DY 1061 working with a copper lamp at a wavelength of $1.790300 \AA$. The measurements were carried out with the Bragg-Brentano geometry. For the material prior to corrosion analysis, phases like $\mathrm{Ni}-\gamma$, $\mathrm{Ni} 0.25 \mathrm{Mo} 0.75, \mathrm{Cr} 0.2 \mathrm{Ni0} .8$ and $\alpha-W$ are indicated. After corrosion through $1000 \mathrm{~h}$ and $4500 \mathrm{~h}$, new phases were created: $\mathrm{NiO}, \mathrm{Cr}_{2} \mathrm{NiO}_{4}, \mathrm{Cr}_{2} \mathrm{O}_{3}, \mathrm{MoS}_{2}$, and $\mathrm{Fe}_{2} \mathrm{O}_{3}$ (Fig. 12). It should be pointed out that, in all measurements after 

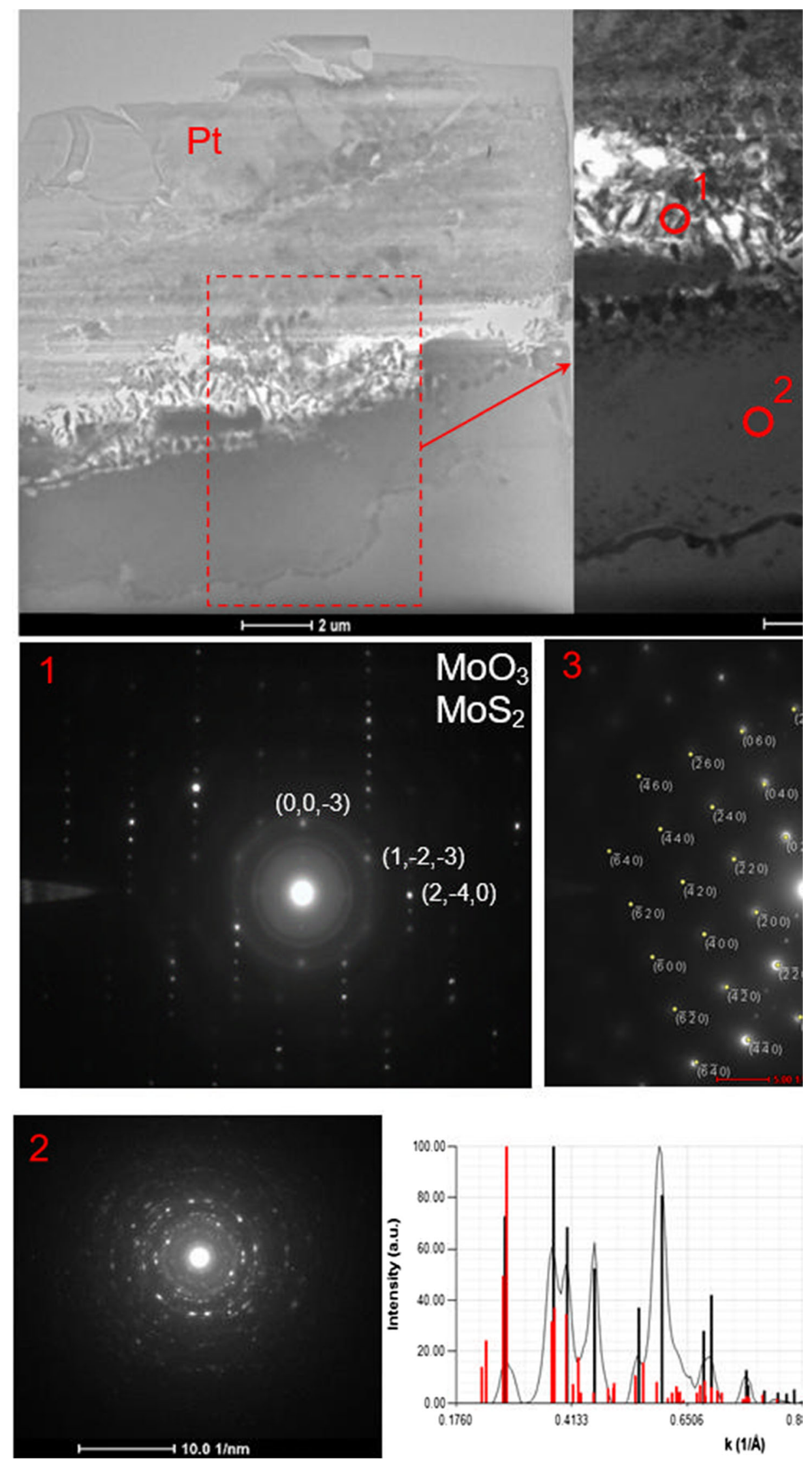

Fig. 11 TEM bright field image of the IN686 coating exposed to gas + ash atmosphere for $1000 \mathrm{~h}$ at $600{ }^{\circ} \mathrm{C}$. Bright field with diffractions correspond to: $1-\mathrm{MoO}_{3}, \mathrm{MoS}_{2}, 2-\mathrm{Cr}_{2} \mathrm{O}_{3}, \mathrm{FeSO}_{4}, 3-\mathrm{Ni}-\gamma$ 


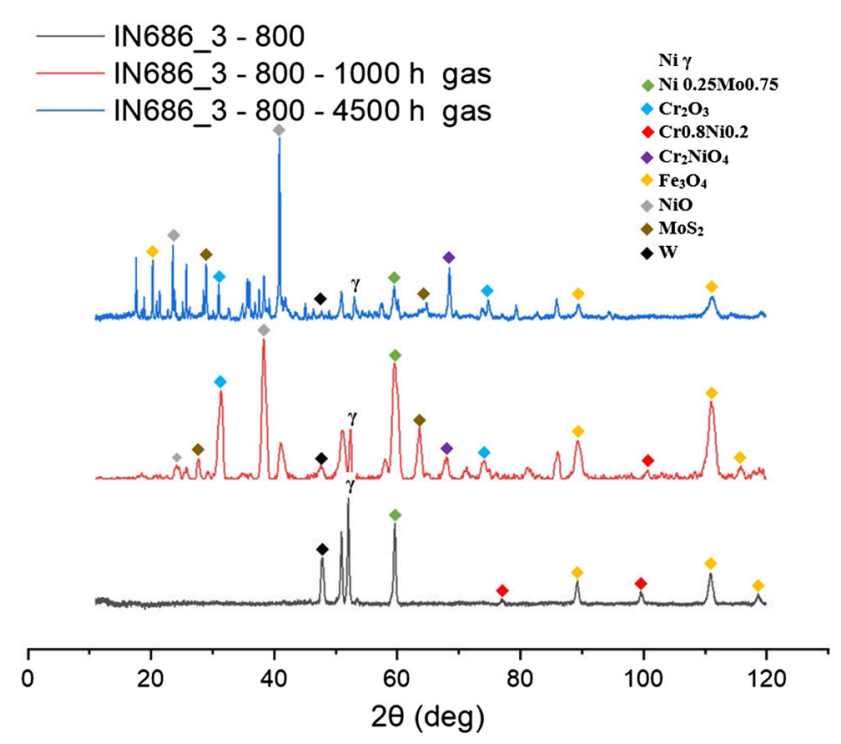

Fig. 12 XRD diagram of the IN686 coating before and after 1000 and $4500 \mathrm{~h}$ of gas corrosion

corrosion, the signal from the base alloy was still identified, meaning that the measurements cross the entire thickness of the oxide scale.

\section{Conclusions}

The results of the experiments showed that coatings from IN686 created with the laser cladding process formed an effective barrier against corrosion of the 13CrMo4-5 steel.

The corrosion processes in gas and gas with ash deposit atmospheres lead to the creation of oxide scale consisting of elements that can restrain further oxidation. The microscopy observations revealed a significant difference between the corrosion of coatings with and without ash deposition. The formation of protective oxide was strongly interrupted by ash elements, which results in further oxidation of the material. The samples characterized by duplex oxide scale: $\mathrm{NiO}$ formed external oxide scale, while $\mathrm{Cr}_{2} \mathrm{NiO}_{4}$ and $\mathrm{MoO}$ created internal oxidation zones with local phases of $\mathrm{MoS}_{2}$ and $\mathrm{FeSO}_{4}$ in the samples with ash deposition. Future work should focus on the thermodynamic calculation of the stability for created oxide scale, which allows the lifetime of this coating to be estimated.

\section{Acknowledgments}

The authors would like to thank BAM-Federal Institute for Materials Research and Testing in Berlin for founding. The lamellae for TEM investigations were prepared at the PAN-Institute of Metallurgy and Materials Engineering in Cracow. The work was also supported by the Ministry of Science and Higher Education of Poland under Contract No. 16.16.110.663.

\section{Open Access}

This article is licensed under a Creative Commons Attribution 4.0 International License, which permits use, sharing, adaptation, distribution and reproduction in any medium or format, as long as you give appropriate credit to the original author(s) and the source, provide a link to the Creative Commons licence, and indicate if changes were made. The images or other third party material in this article are included in the article's Creative Commons licence, unless indicated otherwise in a credit line to the material. If material is not included in the article's Creative Commons licence and your intended use is not permitted by statutory regulation or exceeds the permitted use, you will need to obtain permission directly from the copyright holder. To view a copy of this licence, visit http://creativecommons.org/licenses/by/4.0/.

\section{References}

1. European Commission report, Energy Roadmap 2050, Brussels, 2011

2. C. Cabet, F. Dalle, E. Gaganidze, J. Henry, and H. Tanigawa, FerriticMartensitic Steels for Fission and Fusion Applications, J. Nucl. Mater. 2019, 523, p 510-537

3. P. Henderson, P. Szakalos, R. Pettersson, C. Andersson, and J. Hogberg, Reducing Superheater Corrosion in Wood-Fired Boilers, Mater. Corros., 2006, 2, p 128-134

4. T. Gruber, K. Schulze, R. Scharler, and I. Obernberger, Investigation of the Corrosion Behavior of 13CrMo4-5 for Biomass Fired Boilers with Coupled Online Corrosion and Deposit Probe Measurements, Fuel, 2015, 144, p 15-24

5. J. Adamiec, High Temperature Corrosion of Power Boiler Components Cladded with Nickel Alloys, Mater. Charact., 2009, 60, p 1093-1099

6. M. Oksa, P. Auerkari, J. Salonen, and T. Varis, Nickel-Based HVOF Coatings Promoting High Temperature Corrosion Resistance of Biomass-Fired Power Plant Boilers, Fuel Process. Technol., 2014, 125, p 236-245

7. D. Koclęga, S. Dymek, A. Radziszewska, and J. Huebner, Laser cladding of Inconel 686 overlay weld on low carbon steel, Web of Science, database, 2017, pp. 1327-1332

8. F. Brückner, D. Lepski, and E. Beyer, Modeling the Influence of Process Parameters and Additional Heat Sources on Residual Stresses in Laser Cladding, J. Therm. Spray Technol., 2007, 16, p 355-373

9. D. Koclegga, A. Radziszewska, and A. Kranzmann, The Influence of the Aggressive Environments on the Inconel 686 Coating in HighTemperature Corrosion Experiments, Kraftwerkstechnik 2018, Power Plant Technology, pp. 599-606

10. Z. Chao, T. Wei, H.L. Wen, and H. Liang, Microstructure and Porosity Evaluation in Laser-Cladding Deposited Ni-Based Coatings, Surf. Coat. Technol., 2016, 294, p 122-130

11. Y. Wei, B. Pathiraj, and L. Shaojie, 2D Modeling of Clad Geometry and Resulting Thermal Cycles During Laser Cladding, J. Mater. Process. Technol., 2016, 230, p 217-232

12. E. Mendonça, Y.C. Silvaa, M.F. Mottaa, H.C. Mirandaa, J. Dilleb, and C.C. Silvaa, Electron Detection Modes Comparison for Quantification of Secondary Phases of Inconel 686 Weld Metal, Mater. Charact., 2017, 133, p 10-16

13. M. Solecka, J. Kusinski, A. Kopia, M. Rozmus-Górlikowska, and A. Radziszewska, High-Temperature Corrosion of Ni-base Alloys by Waste Incineration Ashes, A. Phys. Pol. A, 2016, 130, p 1045-1048

14. C. Ostwald and H.J. Grabke, Initial Oxidation and Chromium Diffusion. I. Effect of Surface Working on 9-20\% Cr Steels, Corros. Sci., 2004, 46, p 1113-1127

15. M. Solecka, A. Radziszewska, and B. Rutkowski, New Insight on Study of Ni-base Alloy Clad Layer After Oxidation at $650{ }^{\circ} \mathrm{C}$, Corros. Sci., 2019, 149, p 244-248

16. J. Li, Y. Peng, J. Zhang, S. Jiang, S. Yin, J. Ding, Y. Wu, J. Wu, X. Chen, X. Xia, X. He, and Y. Liu, Cyclic Oxidation of $\mathrm{Ni}_{3}$ Al-based Superalloy, Vacuum, 2019, 169, p 108938 
17. D. Saber, Islam S. Emam, and R. Abdel-Karim, High Temperature Cyclic Oxidation of Ni Based Superalloys at Different Temperatures in Air, J. Alloys Compd., 2017, 719, p 133-141

18. K. Chandra, A. Kranzmann, R. Saliwan Neumann, and F. Rizzo, Comparative Study on High Temperature Oxidation of T92 Steel in Dry and Wet Oxyfuel Environments, Oxid. Met., 2015, 84, p 463-490

19. S.-H. Cho, S.-C. Oh, S.-B. Park, K.-M. Ku, J.-H. Lee, J.-M. Hur, and H.-S. Lee, High Temperature Corrosion Behavior of Ni-based Alloys, Met. Mater. Int., 2012, 18(6), p 939-949
20. Q.C. Sherman, P.W. Voorhees, and L.D. Marks, Thermodynamics of Solute Capture During the Oxidation of Multicomponent Metals, Acta Mater., 2019, 181, p 585-594

21. S. Seetharaman, A. Mclean, R. Guthrie, and S. Sridhar, Treatise on Process Metallurgy, Volume 1, Process Fundamentals, Vol 1, Elsevier, Amsterdam, 2014

Publisher's Note Springer Nature remains neutral with regard to jurisdictional claims in published maps and institutional affiliations. 